\title{
Rapid detection of Enterococcus and vancomycin resistance using recombinase polymerase amplification
}

\author{
Pimchanok Panpru ${ }^{1}$, Arpasiri Srisrattakarn ${ }^{1}$, Nuttanun Panthasri ${ }^{2}$, Patcharaporn Tippayawat ${ }^{1}$, Aroonwadee \\ Chanawong $^{1}$, Ratree Tavichakorntrakool ${ }^{1}$, Jureerut Daduang ${ }^{1}$, Lumyai Wonglakorn ${ }^{3}$, Aroonlug Lulitanond ${ }^{\text {Corresp. } 1}$ \\ ${ }^{1}$ Centre for Research and Development of Medical Diagnostic Laboratories, Faculty of Associated Medical Sciences, Khon Kaen University, Khon Kaen, \\ Thailand \\ 2 The 8th Regional Medical Science Center, Udon Thani, Thailand \\ 3 Clinical Microbiology Unit, Srinagarind Hospital, Khon Kaen University, Khon Kaen, Thailand \\ Corresponding Author: Aroonlug Lulitanond \\ Email address: arolul@kku.ac.th
}

Vancomycin-resistant enterococci (VRE), especially Enterococcus faecium, have been a global concern, often causing serious healthcare-associated infections. We developed a rapid method of isothermal recombinase polymerase amplification (RPA) combined with a lateral-flow (LF) strip for detection of $E$. faecium and vancomycin-resistance genes (vanA and $\operatorname{vanB}$ ) in clinical samples. Specific RPA primer sets and probes for $d d l$ (to detect presence of $E$. faecium), vanA and vanB genes were designed. The RPA reaction was performed under isothermal condition at $37^{\circ} \mathrm{C}$ within $20 \mathrm{~min}$ and read using the LF strip within a further $5 \mathrm{~min}$. A total of 141 positive blood-cultures and 136 stool/rectal swabs were tested using RPA-LF compared to the conventional PCR method. The RPA-LF method exhibited $100 \%$ sensitivity in both blood-culture (60 E. faecium; 35 vanA type and 2 vanB type) and stool/rectal-swab samples (63 E. faecium and 36 vanA type) without crossreaction (100\% specificity). The lower detection limit of the RPA-LF was approximately 10 times better than that of the conventional PCR method. The RPA-LF method is an alternative rapid method with high sensitivity and specificity for diagnosis of $E$. faecium, vanA and $v a n B$, and has a potential to be a point-of-care device for treatment and preventing the spread of VRE. 
1 Rapid detection of Enterococcus and vancomycin resistance 2 using recombinase polymerase amplification

3

Pimchanok Panpru ${ }^{1}$, Arpasiri Srisrattakarn ${ }^{1}$, Nuttanun Panthasri ${ }^{2}$, Patcharaporn Tippayawat ${ }^{1}$, Aroonwadee Chanawong ${ }^{1}$, Ratree Tavichakorntrakool ${ }^{1}$, Jureerut Daduang ${ }^{1}$, Lumyai

Wonglakorn $^{3}$ and Aroonlug Lulitanond ${ }^{1}$

${ }^{1}$ Centre for Research and Development of Medical Diagnostic Laboratories, Faculty of Associated Medical Sciences, Khon Kaen University, Khon Kaen, Thailand

${ }^{2}$ The 8th Regional Medical Science Center, Udon Thani, Thailand ${ }^{3}$ Clinical Microbiology Unit, Srinagarind Hospital, Khon Kaen University, Khon Kaen, Thailand

Corresponding Author:

Aroonlug Lulitanond

Centre for Research and Development of Medical Diagnostic Laboratories, Faculty of Associated Medical Sciences, Khon Kaen University, Khon Kaen 40002, Thailand Email address: arolul@kku.ac.th

\begin{abstract}
Vancomycin-resistant enterococci (VRE), especially Enterococcus faecium, have been a global concern, often causing serious healthcare-associated infections. We established a rapid approach for detecting E. faecium and vancomycin-resistance genes (vanA and vanB) in clinical samples using isothermal recombinase polymerase amplification (RPA) combined with a lateralflow (LF) strip. Specific RPA primer sets and probes for $d d l$ (to identify the presence of $E$. faecium), vanA and $v a n B$ genes were designed. The RPA reaction was performed under isothermal condition at $37^{\circ} \mathrm{C}$ within $20 \mathrm{~min}$ and read using the LF strip within a further $5 \mathrm{~min}$. A total of 141 positive blood-cultures and $136 \mathrm{stool} /$ rectal swab samples were tested using RPA-LF method compared to the conventional PCR method. The RPA-LF method exhibited $100 \%$ sensitivity in both blood-culture (60 E. faecium; $35 \mathrm{vanA}$ type and $2 \mathrm{vanB}$ type) and stool/rectalswab samples (63 E. faecium and 36 vanA type) without cross-reaction ( $100 \%$ specificity). The lower detection limit of the RPA-LF was approximately 10 times better than that of the conventional PCR method. The RPA-LF method is an alternative rapid method with excellent sensitivity and specificity for detecting E. faecium, vanA, and $v a n B$, and it has the potential to be used as a point-of-care device for VRE therapy and prevention.
\end{abstract}

\title{
Introduction
}

Enterococci are found in the gastrointestinal tract of animals and humans as well as in soil, water and food contaminated with feces. They are used as a bacterial indicator of fecal contamination in water and food. The concentration of enterococci in human stool ranged from 
40

41

42

43

44

45

46

47

48

49

50

51

52

53

54

55

56

57

58

59

60

61

62

63

64

65

66

67

68

69

70

71

72

73

74

75

76

77

78

79

$10^{5}-10^{8}$ colony forming unit (CFU)/gram (Gelsomino et al., 2003; Kleessen, Bezirtzoglou \& Mättö et al., 2000). In addition, they are also one of the most prevalent nosocomial pathogens, causing various infections such as urinary tract infections, endocarditis and bacteremia. In the treatment of enterococcal infection, ampicillin remains the antibiotic of choice, while vancomycin is utilized in cases of ampicillin resistance (Kristich, Rice \& Arias, 2014). The increased usage of vancomycin has led to a rise in the number of vancomycin-resistant enterococci (VRE) infections. VRE was found to be $8.10 \%$ prevalent throughout Asia. The Enterococcus faecium showed higher resistance to vancomycin than E. faecalis $(22.4 \%$ vs. 3.7\%) (Shrestha et al., 2021). As shown in a survey from China, Enterococcus spp. was the most common pathogen in nosocomial bloodstream infections, of which $74 \%$ were E. faecium and $20 \%$ were E. faecalis. Furthermore, it was associated with high mortality rate of up to $24 \%$ (Zhang et al., 2017). The National Antimicrobial Resistance Surveillance Centre of Thailand revealed that VRE infection rate of E. faecium has climbed from $0.7 \%$ in 2012 to $6.9 \%$ in 2020 , whereas VRE in E. faecalis has remained at $0.3 \%$ for the past ten years (NARST, 2020). The vanA and $v a n B$ types of VRE are the most common, especially in E. faecium isolates (Hollenbeck \& Rice, 2012). The VRE is associated with high-mortality enterococcal bloodstream infections (Chiang et al., 2017). Most hospitals screen for VRE carriers from rectal swab samples, in order to avoid enterococcal bloodstream infections, prevent the spread of nosocomial infection and establish a successful treatment strategies.

The conventional identification of VRE is generally based on culture, biochemical tests, disk diffusion and determination of minimal inhibitory concentration as well as genotypic methods (Jenkins \& Schuetz, 2012). However, all these methods are time-consuming. Molecular techniques were developed to identify the species of Enterococcus several decades ago (DutkaMalen, Evers \& Courvalin, 1995). Although the polymerase chain reaction (PCR) method is highly sensitive and specific, it has been limited to well-equipped facilities due to the thermocycling requirements. The isothermal amplification techniques have been developed to overcome this constraint, such as recombinase polymerase amplification (RPA), which was initially reported in 2006 (Piepenburg et al., 2006). RPA technique is based on the functions of three proteins comprising recombinase, recombinase loading factor and single-stranded binding (SSB) protein. The nucleoprotein complex is formed by the interaction of an oligonucleotide primer and a recombinase. The recombinase loading factor assists in the combination. The complex searches for the homologous sequences on DNA template and replaces them in the duplex DNA. The formation of primer-DNA complex is stabilized by SSB protein (Yonesaki \& Minagawa, 1985). DNA polymerase initiates the amplification at the end of the primer and finally results in the amount of amplified DNA (Piepenburg et al., 2006). The RPA reaction is enzymatically processed and does not require thermal cycling. The RPA technique can detect very small amount of target DNA molecules. It only requires a low constant temperature (25$42^{\circ} \mathrm{C}$ ) and a 20 min turnaround time. Moreover, the RPA product can be detected by using a variety of methods, such as agarose gel electrophoresis (AGE), real-time quantitative fluorescence or electrochemical detection, etc. Alternatively, the lateral-flow strips (LF) can be 
80

81

82

83

84

85

86

87

88

89

90

91

92

93

94

95

96

97

98

99

100

101

102

103

104

105

106

107

108

109

110

111

112

113

114

115

116

117

118

used to visualize the amplicons in 5 minutes, which is highly practical. The LF strip is a simple tool for qualitative testing, based on sandwiches assay by adding a specific probe into RPA reaction solution. The RPA products would be detected by using specific antibody to the pathogen, tagged with gold nanoparticles which is applied on a paper strip. The results of LF are visible and can be read in 5-10 min (Jauset-Rubio et al., 2016).

Therefore, we developed a rapid and sensitive RPA-LF method for detecting $E$. faecium and its important vancomycin-resistance genes ( $v a n A$ and $v a n B$ ) in positive blood-culture, stool and rectal-swab samples.

\section{Materials \& Methods}

\section{Bacterial isolates and clinical samples}

Ethical approval for this study was obtained from Human Ethics Committee of Khon Kaen University (HE611605). A total of 124 bacterial isolates and 25 clinical samples were collected from patients of a university hospital between January 2018 and December 2020. The 124 bacterial isolates consisted of 20 E. faecium (not VRE), 35 vanA-carrying E. faecium, $48 \mathrm{E}$. faecalis, 5 Enterococcus spp. and 16 non-Enterococcus isolates. The 25 clinical samples were 15 positive blood-culture samples ( 4 E. faecium, 5 E. faecalis, 1 E. casseliflavus, and 5 nonEnterococcus) and 10 rectal swab samples for VRE screening [6 E. faecium (not VRE), 1 vanAcarrying E. faecium, 1 E. faecalis, and 2 group D streptococci]. Additionally, 2 reference strains, $v a n B$-carrying $E$. faecium and vanB-carrying $E$. faecalis, were purchased from Department of Medical Sciences, Ministry of Public Health (Nonthaburi Province, Thailand). All isolates in the Table 1 were identified by using biochemical tests such as bile esculin, $6.5 \%$ sodium chloride ( $\mathrm{NaCl}$ ), arabinose, sorbital and motility tests (Teixeira et al., 2011), then E. faecium was confirmed by conventional PCR amplification of the $d d l$ gene. In addition, van $A$ and $v a n B$ genes were detected by conventional PCR methods. The isolates were stored at $-20^{\circ} \mathrm{C}$ in skimmed milk plus $20 \%$ glycerol. Before testing, all isolates were sub-cultured on blood agar and incubated overnight at $37^{\circ} \mathrm{C}$. Fresh colonies were suspended in $50 \mu \mathrm{L}$ of sterile distilled water then put in boiling water for $10 \mathrm{~min}$. After centrifugation at 13,500 rpm for $1 \mathrm{~min}$, the supernatant was used as the DNA template for either conventional PCR or RPA reaction. All isolates were used to spike in blood and stool samples as well.

\section{Identification of E. faecium (ddl gene) and VRE (vanA and vanB genes) by conventional PCR}

To identify E. faecium and vanA or vanB genotypes of VRE, a region of the $d d l$, and of the vanA and $v a n B$ genes were amplified by PCR reaction using our designed RPA primer set for $d d l$ [ddl-F(RPA) and ddl-R(RPA)], while primers used for vanA and vanB genes were according to a previous report (Table 2) (Dutka-Malen, Evers \& Courvalin, 1995). The $25 \mu \mathrm{L}$ PCR reaction contained $0.2 \mu \mathrm{M}$ of each primer, 1X PCR buffer, $0.2 \mathrm{mM} \mathrm{dNTP,} 2 \mathrm{mM} \mathrm{MgCl}_{2}, 1 \mathrm{U}$ Taq polymerase and $3 \mu \mathrm{L}$ of DNA template. The PCR cycling conditions were $94^{\circ} \mathrm{C}$ for $2 \mathrm{~min}$, followed by 30 cycles of $94^{\circ} \mathrm{C}$ for $1 \mathrm{~min}, 54^{\circ} \mathrm{C}$ for $1 \mathrm{~min}$, and $72^{\circ} \mathrm{C}$ for $1 \mathrm{~min}$, with a final step at 
119

120

121

122

123

124

125

126

127

128

129

130

131

132

133

134

135

136

137

138

139

140

141

142

143

144

145

146

147

148

149

150

151

152

153

154

155

156

157

158

$72^{\circ} \mathrm{C}$ for $10 \mathrm{~min}$. The PCR products were analyzed using $2 \%$ agarose gel electrophoresis (AGE), stained with ethidium bromide solution and visualized under UV transilluminator.

\section{Design of primers and probes for screening}

The single-stranded RPA primers and probes specific for the $d d l$ gene of E. faecium, van $A$ and $v a n B$ genes were designed by using the ClustalW program to align consensus sequences into multiple-sequence alignment. Primers and probes were manually designed according to the guidelines of the manufacturer (TwistDX, Cambridge, UK) and the \%GC content, secondary structure, potential for primer-dimer and hairpin formation were checked using OligoEvaluator ${ }^{\mathrm{TM}}$ and OligoAnalyzer ${ }^{\mathrm{TM}}$. The possibility of false priming with other related genes was examined by using the Primer-BLAST program of the National Center for Biotechnology Information. PCR-AGE and RPA-AGE techniques were used to identify the most appropriate primers for the target amplification.

The final sequences of RPA primers and probes are listed in Table 2. To enable the lateral flow detection, the reverse primer was conjugated with biotin at the 5 'end and the probe (46-52 bp) was designed with a 5'antigenic label (FAM), an internal abasic nucleotide (tetrahydrofuran residue or THF) and a polymerase extension blocking group at the 3'end (TwistDx ${ }^{\mathrm{TM}}$ Limited, 2018).

\section{4. $R P A$ reaction components}

The RPA-AGE reaction was performed using TwistAmp Basic kit (TwistDX, Cambridge, UK). RPA components were mixed according to a previous study (Srisrattakarn et al., 2020). The RPA reaction was incubated at $37^{\circ} \mathrm{C}$ for $20 \mathrm{~min}$ and the reaction was stopped by heating at $65^{\circ} \mathrm{C}$ for $10 \mathrm{~min}$ to eliminate the excess protein (Kapoor et al., 2017). The RPA products were then diluted (1:1) in deionized water before AGE.

The RPA-LF reaction was performed using TwistAmp nfo kits (TwistDx, Cambridge, UK). The RPA master mix contained $2.1 \mu \mathrm{L}$ of each primer $(10 \mu \mathrm{M}), 29.5 \mu \mathrm{L}$ of $1 \times$ rehydration buffer, $0.6 \mu \mathrm{L}$ of probe $(10 \mu \mathrm{M})$, and $11.2 \mu \mathrm{L}$ of deionized water. A total of $45.5 \mu \mathrm{L}$ of master mix were transferred to a dried enzyme pellet tube and mixed well by pipetting. The mixture was divided into four aliquots $(11.37 \mu \mathrm{L}$ each $)$ in $0.2 \mathrm{~mL}$ tubes. DNA template or sample $(0.5 \mu \mathrm{L})$ was added to each tube. The reaction was initiated by the addition of $0.63 \mu \mathrm{L}$ of $280 \mathrm{mM}$ magnesium acetate. The lateral-flow strip (Milenia Genline HybriDetect-1; TwistDx, Cambridge, UK) was used to detect the RPA product by dipping the strip into a mixture of $0.5 \mu \mathrm{L}$ of RPA product and $50 \mu \mathrm{L}$ of phosphate-buffered saline with Tween at room temperature. The result was read within $5 \mathrm{~min}$. The presence of a control band helps to validate successful test: a clearly visible band at both the control and test lines indicate a positive result and the appearance of only a control band indicates a negative result.

\section{Optimization for $R P A$ reaction}

The optimum temperature and incubation time for the RPA reaction was tested by RPAAGE and RPA-LF methods. DNA extracted from $10^{8} \mathrm{CFU} / \mathrm{mL}$ of bacterial suspension was used as template for the RPA reactions. Blank control tube was tested together with each experiment. The main parameters of RPA are amplification temperature and reaction time. The optimal 
159

160

161

162

163

164

165

166

167

168

169

170

171

172

173

174

175

176

177

178

179

180

181

182

183

184

185

186

187

188

189

190

191

192

193

194

195

196

197

198

199

200

conditions of RPA (for all three genes) were found by trying various temperatures $(25,28,31$, 34,37 and $42^{\circ} \mathrm{C}$ ) and various reaction times (5, 10, 15, 20, 25 and $\left.30 \mathrm{~min}\right)$. The final step of all RPA reactions was $65^{\circ} \mathrm{C}$ for $10 \mathrm{~min}$. Before incubation at various temperatures, each reaction tube was transported in a PCR-cooler tube rack. The optimum reaction was determined by the most obvious color on the detection line by the naked eye or the specific band in agarose gel.

\section{The detection limit of PCR-AGE, RPA-AGE and RPA-LF methods}

The detection limits of the three methods were determined by using a 10-fold serial dilution $\left(10^{-1}-10^{-7}\right)$ of DNA extracted from a bacterial suspension (turbidity to 3 McFarland standard) as templates for PCR and RPA reactions. The amplicons were analyzed using AGE and LF methods. Meanwhile, the number of bacteria in each suspension was determined in duplicate by using a spread plate technique. The bacterial colonies were counted and $\mathrm{CFU} / \mathrm{mL}$ calculated. The lowest quantity of DNA template that yielded a positive result was considered to be the detection limit. Each dilution was tested in duplicate.

\section{Performance of RPA-LF for testing clinical samples Positive blood-culture samples}

Each of the 126 bacterial isolates was prepared to a suspension of $10^{5} \mathrm{CFU} / \mathrm{mL}$ in normal saline solution. Spiked blood-culture samples were prepared by mixing $500 \mu \mathrm{L}$ of the bacterial suspension with $10 \mathrm{~mL}$ of healthy human blood and transferred to pre-incubated aerobic culture bottles (RENDER; Zhuhai Meihua Medical Technology Limited, Zhuhai, China) to make a final inoculum of approximately $500 \mathrm{CFU} / \mathrm{mL}$ (Srisrattakarn et al., 2020) and incubated overnight at $37^{\circ} \mathrm{C}$. The number of bacteria after positive signal were approximately $10^{8}-10^{9} \mathrm{CFU} / \mathrm{mL}$ (Smith, 2018). Additionally, 15 positive blood-culture bottles, identified as positive by the BacT/Alert ${ }^{\circledR}$ Virtuo Microbial Detection System (bioMérieux, Marcy l'Etoile, France), from Srinagarind Hospital (a university hospital, Northeast of Thailand) were also tested. All the 141 samples were directly tested using the RPA-LF method for presence of E. faecium and of the vanA gene, while 74 samples were tested for the $v a n B$ gene.

\section{Stool samples}

Spiked stool samples were prepared by mixing $10 \mu \mathrm{L}$ of each of 126 bacterial isolates with approximately $0.1 \mathrm{~g}$ of stool. The samples were then suspended in $990 \mu \mathrm{L}$ of bile esculin broth (BE broth) for enrichment of Enterococcus. After incubated overnight at $37^{\circ} \mathrm{C}$, the colony count were performed from two representative samples which found approximately $10^{8} \mathrm{CFU} / \mathrm{mL}$. The samples were centrifuged at 3,000 rpm for $5 \mathrm{~min}$ to remove stool debris. The supernatant was further centrifuged at $13,000 \mathrm{rpm}$ for $10 \mathrm{~min}$ and all liquid was removed. The microbial sediment was resuspended in distilled water and directly used in the RPA-LF reaction for detection of $E$. faecium and the vanA gene. Ten additional rectal-swab samples from VRE-screened patients attending Srinagarind Hospital were also tested in the same manner.

The performance of the RPA-LF method was evaluated in clinical samples compared with the PCR-AGE method. The results of both methods were blindly read and recorded by three independent research technicians. The final result was reported based on agreement by at least two of the three readers. The sensitivity, specificity, and 95\% confidence interval (CI) of the RPA-LF method were calculated by using a free software VassarStats (http://vassarstats.net/) (Dortet et al., 2018).

PeerJ reviewing PDF | (2021:07:64039:2:0:NEW 28 Oct 2021) 
201

202

203

204

205

206

207

208

209

210

211

212

213

214

215

216

217

218

219

220

221

222

223

224

225

226

227

228

229

230

231

232

233

234

235

236

237

238

239

240

\section{Results}

\section{Optimal temperature and time for $R P A$ reaction}

The RPA-AGE method operated well at a wide range of temperature from $25-42^{\circ} \mathrm{C}$ for the detection of $d d l$, vanA and $v a n B$ genes (Figure S1), whereas the RPA-LF method for the $d d l$ gene provided a strong test-line band at temperatures ranging from $28-42^{\circ} \mathrm{C}$ (Figure $\mathrm{S} 2$ ). The optimum temperature for the further test was $37^{\circ} \mathrm{C}$. Both RPA-AGE and RPA-LF methods performed at $37^{\circ} \mathrm{C}$ yielded an obvious band at the period ranging from 10-30 min for detection of the three genes (Figure S1 and S2, respectively). All blank control tube in each condition provided negative results. Finally, the optimal condition of RPA-LF reaction at $37^{\circ} \mathrm{C}$ for $20 \mathrm{~min}$ was selected for the subsequent testing.

\section{Determination of the detection limit of PCR-AGE, RPA-AGE and RPA-LF method}

The lower limit of the PCR-AGE method for detection of E. faecium, and of vanA- and vanB-carrying VRE were $10^{8}, 10^{6}$ and $10^{7} \mathrm{CFU} / \mathrm{mL}$, respectively, while the detection limit of the RPA-LF and RPA-AGE methods were $10^{7}, 10^{5}$ and $10^{6} \mathrm{CFU} / \mathrm{mL}$, respectively (Figure 1 ). The detection limit of RPA method was 10 times lower than that of the PCR-AGE method.

\section{Detection of bacterial isolates in clinical samples by RPA-LF}

Using the PCR-AGE as the reference method, the detection of E. faecium, and of vanA and $v a n B$ genes in positive blood-culture samples by the RPA-LF method gave sensitivity and specificity of $100 \%$ (E. faecium, 60/60, 81/81; vanA, 35/35, 106/106; vanB, 2/2, 72/72 for positive and negative samples, respectively). Similarly, the detection of these targets in stool/rectal swab samples showed congruent results with the PCR-AGE method. The sensitivity and specificity of the RPA-LF method were $100 \%$ (E. faecium, 63/63, 73/73; vanA, 36/36, 100/100 for positive and negative samples, respectively) (Table 1 and Table S1).

\section{Discussion}

E. faecium is microorganism present in the intestines of humans and animals that can cause various infections including bacteremia, which can lead to considerable morbidity and mortality. In the United States, around 83 percent of $E$. faecium were vancomycin resistant in bloodstream infections patients (Weiner et al., 2016). VRE infections in the bloodstream had a greater mortality rate than those of vancomycin-susceptible Enterococcus (DiazGranados et al., 2005). VRE can survive in various adverse environments such as wide range of temperature (10$45^{\circ} \mathrm{C}$ ) and $\mathrm{pH}(\mathrm{pH} 4.6-9.9), 40 \%$ bile salts and $6.5 \% \mathrm{NaCl}$ (Van den Berghe E, De Winter T \& De Vuyst L, 2006; Foulquie Moreno et al., 2006), particularly in healthcare settings. VRE-carrier screening using stool or rectal swab sample is recommended by Hospital Infection Society and Infection Control Nurses Association to reduce the spread of VRE and related infections in hospitals (Cookson et al., 2006). Development of reliable and sensitive methods for VRE detection is therefore of paramount importance. The RPA-LF method has been adapted to detect many pathogens which requires minimal equipment and a quick turnaround time of $30 \mathrm{~min}$. It has been applied for detection of pathogens in various samples, such as blood (Srisrattakarn et 
241 al., 2020), plasma (Qi et al., 2018), foodstuffs (Du et al., 2018a; Du et al., 2018b), stool

242 (Crannell et al., 2014a) and environmental samples such as plant (Londoño, Harmon \& Polston,

243 2016), soil and water (Saxena et al., 2019). To the best of our knowledge, this is the first report

244 of the application of the RPA-LF method for direct detection of E. faecium and the vanA and

$245 v a n B$ genes in positive blood-culture bottles and stool/rectal-swab samples, facilitating

246 immediate medical intervention.

247 The optimal conditions of the RPA reaction for detection of the three targets (E. faecium

248 and $v a n A$ and $v a n B$ genes) were $37^{\circ} \mathrm{C}$ for $20 \mathrm{~min}$. Several investigations have shown that the

249 RPA-LF can function well at temperatures ranging from $25-45^{\circ} \mathrm{C}$ ( Lu et al., 2021; Peng et al.,

250 2019) and faint band was visible in $5 \mathrm{~min}$ (Du et al., 2018a; Peng et al., 2019; Srisrattakarn et

251 al., 2020; Wu et al., 2020). Similarly, our study found that the RPA worked effectively at a wide

252 temperature range $\left(25-42^{\circ} \mathrm{C}\right)$ and incubation times of 5-30 min could generate a visual signal on

253 the test lines. We chose $37^{\circ} \mathrm{C}$ because all reactions yielded strong bands at the test lines and

254 because low-resource settings usually have equipment allowing incubation at this temperature.

255 The RPA reaction was incubated for $20 \mathrm{~min}$ to prevent false positive results due to unexpected

256 amplification in long time of reaction (Piepenburg et al., 2006). Note that the RPA product was

257 diluted 1:100 with buffer to reduce nonspecific binding of crowding agent and proteins in RPA

258 reactions with the antibodies on a lateral flow strip, and the LF test must be read within 5 min to

259 prevent a false positive result (Rosser et al., 2015; Saldarriaga et al., 2016; Wu et al., 2016).

260 The RPA-LF method for detection of the three genes was 10 times more sensitive (lower

261 detection limit) than the conventional PCR method, whereas the detection limits of the RPA-LF

262 and RPA-AGE methods were equal. The RPA reaction has higher sensitivity than the PCR

263 method because the RPA primer is designed according to the TwistAmp ${ }^{\circledR}$ kit formulations

264 which indicated the supporting to the RPA reaction. The RPA reactions contain high level of

265 ATP-burning recombinase that the fuel is consumed typically within around 25-30 min. RPA

266 primers (30-35 bp) are longer than the typical conventional PCR primers for the amplification to

267 give a DNA product of 100-500 bp (TwistDx ${ }^{\mathrm{TM}}$ Limited, 2018). The primers length of greater

268 than 28 bp bind strongly to the recombinase protein. These complex searches for the homologous

269 sequences in the double-stranded DNA and invading the DNA template. The recombinase-

270 primer complex stimulates the ATP hydrolysis in RPA reaction. The complex will split when the

271 ATP is hydrolyzed, and the recombinase will bind to the primer to begin the next reaction

272 immediately (Piepenburg et al., 2006). Therefore, the RPA has higher sensitivity and gives a

273 faster result than the conventional PCR reaction. The detection limit of RPA in our study was

274 lower than the conventional PCR, which was consistent with the study of Wang et al. (2016).

275 The performance of the RPA-LF for detection of pathogens in both blood culture and

276 rectal swab/stool samples showed $100 \%$ sensitivity and 100\% specificity with no cross reactions.

277 The method has been successful for direct detection of E. faecium and vanA or vanB genes in

278 positive blood-culture samples. Several studies showed that some components of blood, mainly

279 heme (Akane et al., 1994), leukocyte DNA (Morata, Queipo-Ortuño \& de Dios Colmenero,

280 1998), immunoglobulin G in plasma (Al-Soud, Jönsson \& Râdström, 2000), and various 
281

282

283

284

285

286

287

288

289

290

291

292

293

294

295

296

297

298

299

300

301

302

303

304

305

306

307

308

309

310

311

312

313

314

315

316

317

318

319

inhibitors in the environment (Jiang et al., 2005) are major inhibitors of the PCR reaction. The RPA-LF technique was shown to be successful even in serum, heparin and hemoglobin (Kersting et al., 2014). However, some technical problems of the RPA-LF reaction were encountered during the study, when tested with fecal samples directly. It is known that fecal samples contain various substances that influence the reactions (Schrader et al., 2012). Additionally, the culture medium for bacterial enrichment or the solution for sample extraction may contain inhibitors. In this study, the bile esculin inhibited the RPA-LF reaction resulting in negative results (Figure S3). The cetyltrimethyl ammonium bromide in DNA extraction buffer was reported to have a strong inhibitory effect on RPA reactions (Valasevich \& Schneider, 2017). Therefore, sample preparation steps are crucial to reduce those substances. In our study, the faecal debris and medium broth were eliminated as feasible after the incubation period. Then the suspected microbial suspension was used as sample for the RPA-LF reaction, which yielded satisfactory results despite the lack of DNA extraction. The RPA-LF reaction can tolerate crude samples with minimal sample preparation steps (Silva et al., 2018) and in the presence of many inhibitors (Kersting et al., 2014). In comparison to the results obtained from conventional PCR method and the developed RPA method of Yin et al. (2017), the RPA method has a high sensitivity and specificity. However, development of RPA for detection of Burkholderia pseudomallei in blood samples (Peng et al., 2019) and detection of group B streptococci in vaginal/anal samples (Daher et al., 2014) were compared to real-time PCR method, the latter report showed that RPA assay had 96 and $100 \%$ of sensitivity and specificity, respectively.

In our detection limit study, the result of conventional PCR reaction was negative, while that of the RPA reaction was positive. This occurred when there was low number of bacteria in the sample which affected the capability of the detection method. The number of bacteria in each sample in this study was at least $10^{8} \mathrm{CFU} / \mathrm{mL}$, which could be detected from both RPA and conventional PCR. As a result, the calculated values of sensitivity and specificity were $100 \%$. However, the real-time PCR method should be used as a reference method to support in the further research, particularly for the detection of samples containing a low number of bacteria.

The RPA method uses simple incubation conditions and requires common laboratory equipment such as heat block and water bath. Moreover, the RPA processes for DNA amplification can be incubated at the body temperature (Crannell, Rohrman, Richards-Kortum et al., 2014b). While the conventional or real-time PCR methods and GeneXpert need special equipment such as thermocycle machine or GeneXpert instrument (Cepheid, Sunnyvale, CA,USA). RPA method displays a faster time-to-result ( $<20 \mathrm{~min})$ than the PCR method $(>1.5 \mathrm{hr})$ and the GeneXpert ( $45 \mathrm{~min}$ ) (Moore \& Jaykus, 2017; Cepheid, Sunnyvale, CA,USA). These are the main benefits of the RPA for VRE detection at the point of care setting. Furthermore, one of the most important factors to consider is the cost. The RPA platform is more cost-effective $(\sim 3.70)$ compared with the costs of conventional PCR $(\sim 2.60)$ and real-time PCR $(\sim 25)(A l-$ Siyabi et al., 2013; Richards et al., 2019; Zhang et al., 2014). However, the volume of RPA reaction can be reduced to $12.5 \mu \mathrm{L}$ leading to decrease the cost of RPA-LF method to $\sim \$ 2.28$ 
320

321

322

323

324

325

326

327

328

329

330

331

332

333

334

335

336

337

338

339

340

341

342

343

344

345

346

347

348

349

350

351

352

353

354

355

356

357

358

359

per test ( $\sim \$ 0.83$ for RPA reaction and $\sim \$ 1.45$ for the haft of commercial LF strip), which was adopted in this study.

One limitation of this study is the small number of clinical samples that we used. VRE bloodstream infections are rare in the hospital, limiting the availability of such samples. Therefore, additional tests were carried out using spiked samples. However, additional clinical samples for testing are still needed, especially those of the vanB-type VRE, which are particularly uncommon in our area. In addition, E. faecalis can cause a variety of nosocomial infections such as urinary tract infections but the prevalence of vancomycin-resistant $E$. faecalis $(0.3 \%)$ was lower than E. faecium (6.9\%) in our area (NARST, 2020). Therefore, the method for detection of $E$. faecalis should be further studied. Another limitation in this study was a shortage supply of Twist Amp nfo kit from the manufacturer, forcing us to test a limited number of samples, especially for the vanB gene and lacking of the RPA-LF test for E. faecalis.

\section{Conclusions}

The RPA-LF method is rapid (within $30 \mathrm{~min}$ ), user-friendly test for detecting $E$. faecium and $v a n A$ or $v a n B$ genes. It exhibits high sensitivity and specificity. This is a suitable candidate for use in low-resource laboratories and would also be useful for infection-control purposes to prevent the spread of VRE in hospitals.

\section{Acknowledgements}

We are grateful to Assoc. Prof. Chotechana Wilailuckana, Centre for Research and Development of Medical Diagnostic Laboratories, Faculty of Associated Medical Sciences, Khon Kaen University, for kindly providing the 20 vanA-carrying E. faecium isolate; and staff of Clinical Microbiology Laboratory, Srinagarind Hospital, Khon Kaen, Thailand, for collecting the clinical isolates. We would like to acknowledge Prof. David Blair, for editing the MS via Publication Clinic KKU, Thailand.

\section{References}

Al-Siyabi T, Binkhamis K, Wilcox M, Wong S, Pabbaraju K, Tellier R, Hatchette TF, LeBlanc JJ. 2013. A cost effective real-time PCR for the detection of adenovirus from viral swabs. Virology journal 10:184 DOI: 10.1186/1743-422X-10-184.

Al-Soud WA, Jönsson LJ, Râdström P. 2000. Identification and characterization of immunoglobulin $\mathrm{G}$ in blood as a major inhibitor of diagnostic PCR. Journal of clinical microbiology 38:345-350 DOI: 10.1128/JCM.38.1.345-350.2000.

Akane A, Matsubara K, Nakamura H, Takahashi S, Kimura K. 1994. Identification of the heme compound copurified with deoxyribonucleic acid (DNA) from bloodstains, a major inhibitor of polymerase chain reaction (PCR) amplification. Journal of forensic sciences 39:362-372. Chiang HY, Perencevich EN, Nair R, Nelson RE, Samore M, Khader K, Chorazy ML, Herwaldt LA, Blevins A, Ward MA, Schweizer ML. 2017. Incidence and outcomes associated with infections caused by vancomycin-resistant Enterococci in the United States: Systematic 
360

361

362

363

364

365

366

367

368

369

370

371

372

373

374

375

376

377

378

379

380

381

382

383

384

385

386

387

388

389

390

391

392

393

394

395

396

397

398

literature review and meta-analysis. Infection control and hospital epidemiology 38:203-215 DOI: $10.1017 /$ ice. 2016.254 .

Cookson BD, Macrae MB, Barrett SP, Brown DF, Chadwick C, French GL, Hateley P, Hosein IK, Wade JJ. 2006. Guidelines for the control of glycopeptide-resistant enterococci in hospitals. The Journal of hospital infection 62:6-21 DOI: 10.1016/j.jhin.2005.02.016.

Crannell ZA, Castellanos-Gonzalez A, Irani A, Rohrman B, White AC, Richards-Kortum R. 2014a. Nucleic acid test to diagnose cryptosporidiosis: lab assessment in animal and patient specimens. Analytical chemistry 86:2565-2571 DOI: 10.1021/ac403750z.

Crannell ZA, Rohrman B, Richards-Kortum R. 2014b. Equipment-free incubation of recombinase polymerase amplification reactions using body heat. PLOS ONE 9:e112146 DOI: 10.1371/journal.pone.0112146.

Daher RK, Stewart G, Boissinot M, Bergeron MG. 2014. Isothermal recombinase polymerase amplification assay applied to the detection of group B streptococci in vaginal/anal samples. Clinical Chemistry 60:660-666 DOI: 10.1373/clinchem.2013.213504.

DiazGranados CA, Zimmer SM, Klein M, Jernigan JA. 2005. Comparison of mortality associated with vancomycin-resistant and vancomycin-susceptible enterococcal bloodstream infections: a meta-analysis. Clinical infectious diseases 41:327-333 DOI: 10.1086/430909.

Dortet L, Tandé D, de Briel D, Bernabeu S, Lasserre C, Gregorowicz G, Jousset AB, Naas T. 2018. MALDI-TOF for the rapid detection of carbapenemase-producing Enterobacteriaceae: comparison of the commercialized MBT STAR ${ }^{\circledR}$-Carba IVD Kit with two inhouse MALDITOF techniques and the RAPIDEC ${ }^{\circledR}$ CARBA NP. The Journal of antimicrobial chemotherapy 73:2352-2359 DOI: 10.1093/jac/dky209.

Du XJ, Zang YX, Liu HB, Li P, Wang S. 2018a. Rapid detection of Staphylococcus aureus via recombinase polymerase amplification combined with lateral flow strip. Food analytical methods 11:2296-2306 DOI: 10.1007/s12161-018-1200-7.

Du XJ, Zang YX, Liu HB, Li P, Wang S. 2018b. Recombinase polymerase amplification combined with lateral flow strip for Listeria monocytogenes detection in food. Journal of food science 83:1041-1047 DOI: 10.1111/1750-3841.14078.

Dutka-Malen S, Evers S, Courvalin P. 1995. Detection of glycopeptide resistance genotypes and identification to the species level of clinically relevant enterococci by PCR. Journal of clinical microbiology 33:24-27 DOI: 10.1128/jcm.33.1.24-27.1995.

Foulquié Moreno MR, Sarantinopoulos P, Tsakalidou E, De Vuyst L. 2006. The role and application of enterococci in food and health. International journal of food microbiology 106: 1-24 DOI: 10.1016/j.ijfoodmicro.2005.06.026.

Gelsomino R, Vancanneyt M, Cogan TM, Swings J. 2003. Effect of raw-milk cheese consumption on the enterococcal flora of human feces. Applied and environmental microbiology 69:312-319 DOI: 10.1128/AEM.69.1.312-319.2003.

Hollenbeck BL, Rice LB. 2012. Intrinsic and acquired resistance mechanisms in Enterococcus. Virulence 3:421-433 DOI: 10.4161/viru.21282. 
399

400

401

402

403

404

405

406

407

408

409

410

411

412

413

414

415

416

417

418

419

420

421

422

423

424

425

426

427

428

429

430

431

432

433

434

435

436

437

438

Jauset-Rubio M, Svobodová M, Mairal T, McNeil C, Keegan N, Saeed A, Abbas MN, ElShahawi MS, Bashammakh AS, Alyoubi AO, O Sullivan CK. 2016. Ultrasensitive, rapid and inexpensive detection of DNA using paper based lateral flow assay. Scientific reports 6:37732 DOI: $10.1038 /$ srep37732.

Jenkins SG, Schuetz AN. 2012. Current concepts in laboratory testing to guide antimicrobial therapy. Mayo Clinic proceedings 87:290-308 DOI: 10.1016/j.mayocp.2012.01.007.

Jiang J, Alderisio KA, Singh A, Xiao L. 2005. Development of procedures for direct extraction of Cryptosporidium DNA from water concentrates and for relief of PCR inhibitors. Applied and environmental microbiology 71:1135-1141 DOI: 10.1128/AEM.71.3.1135-1141.2005.

Kapoor R, Srivastava N, Kumar S, Saritha RK, Sharma SK, Jain RK, Baranwal VK. 2017. Development of a recombinase polymerase amplification assay for the diagnosis of banana bunchy top virus in different banana cultivars. Archives of virology 162:2791-2796 DOI: 10.1007/s00705-017-3399-9.

Kersting S, Rausch V, Bier FF, von Nickisch-Rosenegk M. 2014. Rapid detection of Plasmodium falciparum with isothermal recombinase polymerase amplification and lateral flow analysis. Malaria journal 13:99 DOI: 10.1186/1475-2875-13-99.

Kleessen B, Bezirtzoglou E, Mättö J. 2000. Culture-based knowledge on biodiversity, development and stability of human gastrointestinal microflora. Microbial Ecology in Health and Disease 12:53-63 DOI: 10.3402/mehd.v12i2.8104.

Kristich CJ, Rice LB, Arias CA. 2014. Enterococcal infection treatment and antibiotic resistance. In: Gilmore MS, Clewell DB, Ike Y, Shankar N, ed. Enterococci: From Commensals to Leading Causes of Drug Resistant Infection. Boston: Massachusetts Eye and Ear Infirmary.

Londoño MA, Harmon CL, Polston JE. 2016. Evaluation of recombinase polymerase amplification for detection of begomoviruses by plant diagnostic clinics. Virology journal 13:48 DOI: 10.1186/s12985-016-0504-8.

Lu X, Xu H, Song W, Yang Z, Yu J, Tian Y, Jiang M, Shen D, Dou D. 2021. Rapid and simple detection of Phytophthora cactorum in strawberry using a coupled recombinase polymerase amplification-lateral flow strip assay. Phytopathology research 3:12 DOI: 10.1186/s42483021-00089-8.

Moore MD, Jaykus LA. 2017. Recombinase polymerase amplification: a promising point-of-care detection method for enteric viruses. Future Virology 12:421-429 DOI: 10.2217/fvl-20170034.

Morata P, Queipo-Ortuño MI, de Dios Colmenero J. 1998. Strategy for optimizing DNA amplification in a peripheral blood PCR assay used for diagnosis of human brucellosis. Journal of clinical microbiology 36:2443-2446 DOI: 10.1128/JCM.36.9.2443-2446.1998.

National Antimicrobial Resistance Surveillance Center Thailand. 2020. Antimicrobial resistance 2000-2020. Available at http://narst.dmsc.moph.go.th/(accessed 21 September 2021).

Peng Y, Zheng X, Kan B, Li W, Zhang W, Jiang T, Lu J, Qin A. 2019. Rapid detection of Burkholderia pseudomalle $i$ with a lateral flow recombinase polymerase amplification assay. PLoS One 14:e0213416 DOI: 10.1371/journal.pone.0213416. 
439 Piepenburg O, Williams CH, Stemple DL, Armes NA. 2006. DNA detection using

440

441

442

443

444

445

446

447

448

449

450

451

452

453

454

455

456

457

458

459

460

461

462

463

464

465

466

467

468

469

470

471

472

473

474

475

476

477

recombination proteins. PLoS biology 4:e204 DOI: 10.1371/journal.pbio.0040204.

Qi Y, Shao Y, Rao J, Shen W, Yin Q, Li X, Chen H, Li J, Zeng W, Zheng S, Liu S, Li Y. 2018. Development of a rapid and visual detection method for Rickettsia rickettsii combining recombinase polymerase assay with lateral flow test. PLoS One 13:e0207811 DOI: 10.1371/journal.pone.0207811.

Richards SM, Mitchell KJ, Tobler R, Cooper A. 2019. Recombinase polymerase amplification (RPA) versus PCR for ancient DNA library amplification. PeerJ Preprints 7:e27544v1 DOI: $10.7287 /$ peerj.preprints.27544v1.

Rosser A, Rollinson D, Forrest M, Webster BL. 2015. Isothermal recombinase polymerase amplification (RPA) of Schistosoma haematobium DNA and oligochromatographic lateral flow detection. Parasites \& vectors 8:446 DOI: 10.1186/s13071-015-1055-3.

Saldarriaga OA, Castellanos-Gonzalez A, Porrozzi R, Baldeviano GC, Lescano AG, de Los Santos MB, Fernandez OL, Saravia NG, Costa E, Melby PC, Travi BL. 2016. An innovative field-applicable molecular test to diagnose cutaneous Leishmania Viannia spp. infections. PLoS neglected tropical diseases 10:e0004638 DOI: 10.1371/journal.pntd.0004638.

Saxena A, Pal V, Tripathi NK, Goel AK. 2019. Development of a rapid and sensitive recombinase polymerase amplification-lateral flow assay for detection of Burkholderia mallei. Transboundary and emerging diseases 66:1016-1022. DOI: 10.1111/tbed.13126.

Schrader C, Schielke A, Ellerbroek L, Johne R. 2012. PCR inhibitors-occurrence, properties and removal. Journal of applied microbiology 113:1014-1026 DOI: 10.1111/j.13652672.2012.05384.x.

Shrestha S, Kharel S, Homagain S, Aryal R, Mishra SK. 2021. Prevalence of vancomycinresistant enterococci in Asia-A systematic review and meta-analysis. Journal of clinical pharmacy and therapeutics 46:1226-1237 DOI: 10.1111/jcpt.13383.

Silva G, Oyekanmi J, Nkere CK, Bömer M, Kumar PL, Seal SE. 2018. Rapid detection of potyviruses from crude plant extracts. Analytical biochemistry 546:17-22 DOI: 10.1016/j.ab.2018.01.019.

Smith KP. 2018. Predictive Value of Blood Culture Time to Positivity. Available at https://asm.org/Articles/2018/November/Predictive-Value-of-Blood-Culture-Time-toPositivi (accessed 29 September 2021).

Srisrattakarn A, Tippayawat P, Chanawong A, Tavichakorntrakool R, Daduang J, Wonglakorn L, Sooksongsoontorn P, Lulitanond A. 2020. Direct detection of methicillin-resistant in Staphylococcus spp. in positive blood culture by isothermal recombinase polymerase amplification combined with lateral flow dipstick assay. World journal of microbiology \& biotechnology 36:162 DOI: 10.1007/s11274-020-02938-8.

Teixeira LM, Carvalho Mda G, Facklam R, Shewmaker PL. 2011. Enterococcus. In Murray PR, Baron EJ, Pfaller MA, Jorgensen JH and Yolken RH, ed. Manual of Clinical Microbiology. $10^{\text {th }}$ ed. Washinton D.C.: ASM Press, 350-364.

Peer] reviewing PDF | (2021:07:64039:2:0:NEW 28 Oct 2021) 
478 TwistDx ${ }^{\mathrm{TM}}$ Limited. 2018. TwistAmp ${ }^{\circledR}$ manuals. Available at https://www.twistdx.co.uk/en/

479

480

481

482

483

484

485

486

487

488

489

490

491

492

493

494

495

496

497

498

499

500

501

502

503

504

505

506

507

508

509

510

511

512

513

514

515

516

support/manuals/twistamp-manuals (accessed 21 September 2021).

Valasevich N, Schneider B. 2017. Rapid detection of Candidatus Phytoplasma mali by recombinase polymerase amplification assays. Journal of Phytopathology 165:762-770 DOI: $10.1111 /$ jph.12616.

Wang J, Liu L, Li R, Wang J, Fu Q, Yuan W. 2016. Rapid and sensitive detection of canine parvovirus type 2 by recombinase polymerase amplification. Archives of virology 161:10151018 DOI: $10.1007 / \mathrm{s} 00705-015-2738-y$.

Weiner LM, Webb AK, Limbago B, Dudeck MA, Patel J, Kallen AJ, Edwards JR, Sievert DM. 2016. Antimicrobial-resistant pathogens associated with healthcare-associated infections: summary of data reported to the National Healthcare Safety Network at the Centers for Disease Control and Prevention, 2011-2014. Infection control and hospital epidemiology 37:1288-1301 DOI: 10.1017/ice.2016.174.

Wu H, Zhao P, Yang X, Li J, Zhang J, Zhang X, Zeng Z, Dong J, Gao S, Lu C. 2020. A recombinase polymerase amplification and lateral flow strip combined method that detects Salmonella enterica Serotype Typhimurium with no worry of primer-dependent artifacts. Frontiers in microbiology 11:1015 DOI: 10.3389/fmicb.2020.01015.

Wu YD, Zhou DH, Zhang LX, Zheng WB, Ma JG, Wang M, Zhu XQ, Xu MJ. 2016. Recombinase polymerase amplification (RPA) combined with lateral flow (LF) strip for equipment-free detection of Cryptosporidium spp. oocysts in dairy cattle feces. Parasitology research 115:3551-3555 DOI: 10.1007/s00436-016-5120-4.

Van den Berghe E, De Winter T, De Vuyst L. 2006. Enterocin A production by Enterococcus faecium FAIR-E 406 is characterised by a temperature- and $\mathrm{pH}$-dependent switch-off mechanism when growth is limited due to nutrient depletion. International journal of food microbiology 107: 159-170 DOI: 10.1016/j.ijfoodmicro.2005.08.027.

Yin F, Liu J, Liu A, Li Y, Luo J, Guan G, Yin H. 2017. Rapid diagnosis of Theileria annulata by recombinase polymerase amplification combined with a lateral flow strip (LF-RPA) in epidemic regions. Veterinary parasitology 237:125-129 DOI: 10.1016/j.vetpar.2017.02.019.

Yonesaki T, Minagawa T. 1985. T4 phage gene uvsX product catalyzes homologous DNA pairing. The EMBO journal 4:3321-3327.

Zhang S, Ravelonandro M, Russell P, McOwen N, Briard P, Bohannon S, Vrient A. 2014. Rapid diagnostic detection of plum pox virus in Prunus plants by isothermal AmplifyRP(®) using reverse transcription-recombinase polymerase amplification. Journal of virological methods 207:114-120. DOI: 10.1016/j.jviromet.2014.06.026.

Zhang Y, Du M, Chang Y, Chen LA, Zhang Q. 2017. Incidence, clinical characteristics, and outcomes of nosocomial Enterococcus spp. bloodstream infections in a tertiary-care hospital in Beijing, China: a four-year retrospective study. Antimicrobial resistance and infection control 6:73 DOI: 10.1186/s13756-017-0231-y.

PeerJ reviewing PDF | (2021:07:64039:2:0:NEW 28 Oct 2021) 


\section{Table $\mathbf{1}$ (on next page)}

Results of PCR-AGE and RPA-LF methods for detection of $E$. faecium, vanA and vanB genes

ND, not done. ${ }^{a}$ The conventional PCR method was tested using DNA from bacterial colonies. ${ }^{b}$ RPA-LF method for $E$. faecium and vanA was tested in positive blood culture samples. ${ }^{\mathrm{C}}$ RPALF method for $E$. faecium and vanA was tested in stool/rectal swab samples. ${ }^{\text {R }}$ RPA-LF method for vanB was tested in 74 positive blood culture samples. 
1 Table 1 Results of PCR-AGE and RPA-LF methods for detection of E. faecium, vanA and vanB genes

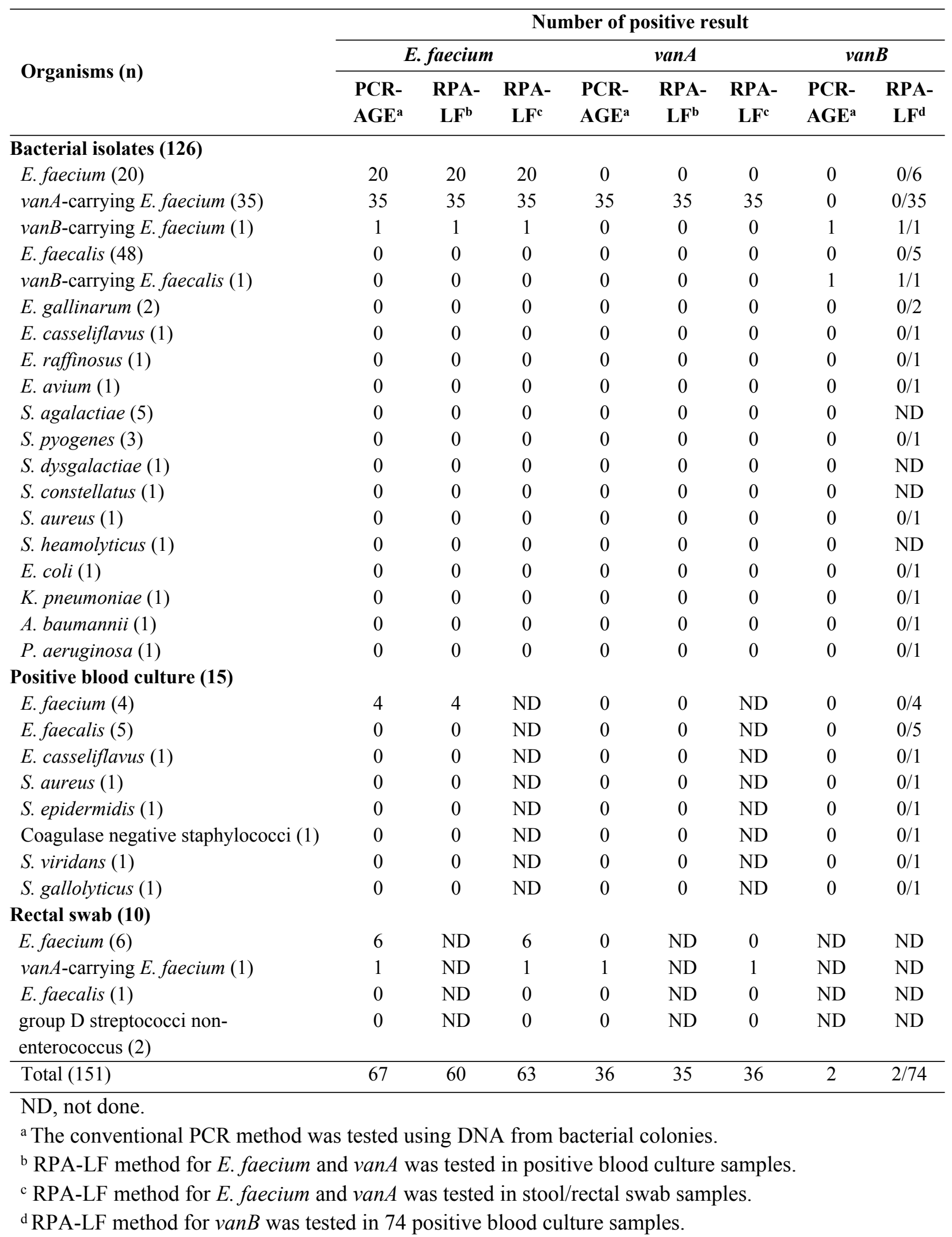




\section{Table 2 (on next page)}

Single strand primers and probes used for PCR and RPA reactions

${ }^{a}$ The $d d l$ RPA primer pair was used in both PCR and RPA reaction. F, forward primer; R, reverse primer; FAM, 6-Carboxyfluorescein; THF, tetrahydrofuran residue, an internal abasic nucleotide; C3-Spacers, a polymerase extension blocking group 
1 Table 2 Single strand primers and probes used for PCR and RPA reactions Primers and probes used for PCR and RPA reactions

\begin{tabular}{|c|c|c|c|c|c|c|}
\hline $\begin{array}{l}\text { Target } \\
\text { genes }\end{array}$ & Primer name & Sequence $\left(5^{\prime}-3^{\prime}\right)$ and modification & $\begin{array}{c}\text { Product } \\
\text { length }\end{array}$ & $\begin{array}{l}\text { Primer } \\
\text { location } \\
\end{array}$ & $\begin{array}{c}\text { Genbank } \\
\text { accession no. }\end{array}$ & Reference \\
\hline$d d l$ & $\begin{array}{l}d d l-\mathrm{F}(\mathrm{RPA})^{\mathrm{a}} \\
d d l-\mathrm{R}(\mathrm{RPA})^{\mathrm{a}} \\
d d l \text {-R (RPA-LF) } \\
d d l-\mathrm{P} \text { (RPA-LF) }\end{array}$ & $\begin{array}{l}\text { ACCCAAGTGGACAGACAGAGGAAGGCTTTA } \\
\text { TTCCATCTTCCCCGTTTGGCCCATGTAAAACT } \\
\text { Biotin-CATAAGGCATATTCAATGTCTCTAAGAAGC } \\
\text { FAM-CGGGAGAAATCAAAGAAGAAGGAGCCATCG- } \\
\text { [THF]-TTTTCCAGTTTTACA-C3-Spacer }\end{array}$ & $156 \mathrm{bp}$ & $\begin{array}{l}242-271 \\
368-397 \\
\end{array}$ & $\overline{\mathrm{AY} 489046.1}$ & $\begin{array}{l}\text { This study } \\
\text { This study }\end{array}$ \\
\hline vanA & $\begin{array}{l}\text { van } A-\mathrm{F}(\mathrm{PCR}) \\
\text { van } A-\mathrm{R}(\mathrm{PCR}) \\
\text { van } A-\mathrm{F} \text { (RPA) } \\
\text { van } A \text {-R (RPA) } \\
\text { van } A \text {-R (RPA-LF) } \\
\text { van } A \text {-P (RPA-LF) }\end{array}$ & $\begin{array}{l}\text { GGGAAAACGACAATTGC } \\
\text { GTACAATGCGGCCGTTA } \\
\text { TTGCGCGGAATGGGAAAACGACAATTGCTATT } \\
\text { CAAAAGGGATACCGGACAATTCAAACAGACC } \\
\text { Biotin-CAAAAGGGATACCGGACAATTCAAACAGACC } \\
\text { FAM-GATGTAGCATTTTCAGCTTTGCATGGCAAG- } \\
\text { [THF]-CAGGTGAAGATGGAT-C3-Spacer }\end{array}$ & $\begin{array}{l}941 \mathrm{bp} \\
194 \mathrm{bp}\end{array}$ & $\frac{\frac{176-192}{891-907}}{\underline{165-196}}$ & $\begin{array}{l}\mathrm{NC} \quad 014475.1 \\
\mathrm{NC} \quad 014475.1 \\
\end{array}$ & $\begin{array}{l}\text { Dutka-Malen, Evers } \\
\text { \& Courvalin (1995) } \\
\text { This study } \\
\text { This study }\end{array}$ \\
\hline $\operatorname{van} B$ & $\begin{array}{l}\operatorname{van} B-\mathrm{F}(\mathrm{PCR}) \\
\operatorname{van} B-\mathrm{R}(\mathrm{PCR}) \\
\operatorname{van} B-\mathrm{F}(\mathrm{RPA}) \\
\operatorname{van} B-\mathrm{R}(\mathrm{RPA}) \\
\operatorname{van} B-\mathrm{R}(\mathrm{RPA}-\mathrm{LF}) \\
\operatorname{van} B-\mathrm{P}(\mathrm{RPA}-\mathrm{LF})\end{array}$ & $\begin{array}{l}\text { ATGGGAAGCCGATAGTC } \\
\text { GATTTCGTTCCTCGACC } \\
\text { GAGGATGATTTGATTGTCGGCGAAGTGGAT } \\
\text { TTTGCCGTTTCTTGCACCCGATTTCGTTCCTC } \\
\text { Biotin- TTTGCCGTTTCTTGCACCCGATTTCGTTCCTC } \\
\text { FAM-CAAATCCGGCTGAGCCACGGTATCTTCCGC- } \\
\text { [THF]-TCCATCAGGAAAACG-C3-Spacer }\end{array}$ & $\begin{array}{l}635 \mathrm{bp} \\
165 \mathrm{bp}\end{array}$ & $\frac{\frac{174-190}{792-808}}{\frac{664-693}{765-795}}$ & $\begin{array}{l}\text { NC } \quad 004668.1 \\
\mathrm{NC} \quad 004668.1 \\
\end{array}$ & $\begin{array}{l}\text { Dutka-Malen, Evers } \\
\text { \& Courvalin (1995) } \\
\text { This study } \\
\text { This study }\end{array}$ \\
\hline
\end{tabular}

\footnotetext{
$2 \quad{ }^{\text {a }}$ The $d d l$ RPA primer pair was used in both PCR and RPA reaction.
}

3 F, forward primer; R, reverse primer; FAM, 6-Carboxyfluorescein; THF, tetrahydrofuran residue, an internal abasic nucleotide; C3-Spacers, a

4 polymerase extension blocking group 


\section{Figure 1}

Detection limits of the RPA-AGE and RPA-LF methods compared with those of the PCR method for detection of E. faecium (A), vanA (B) and vanB (C) genes.

Each sample gave the same result after being tested twice. Marker, GeneRuler DNA Ladder Mix (Thermo Scientific, California, USA); +, positive result; +w, weakly positive result; -, negative result

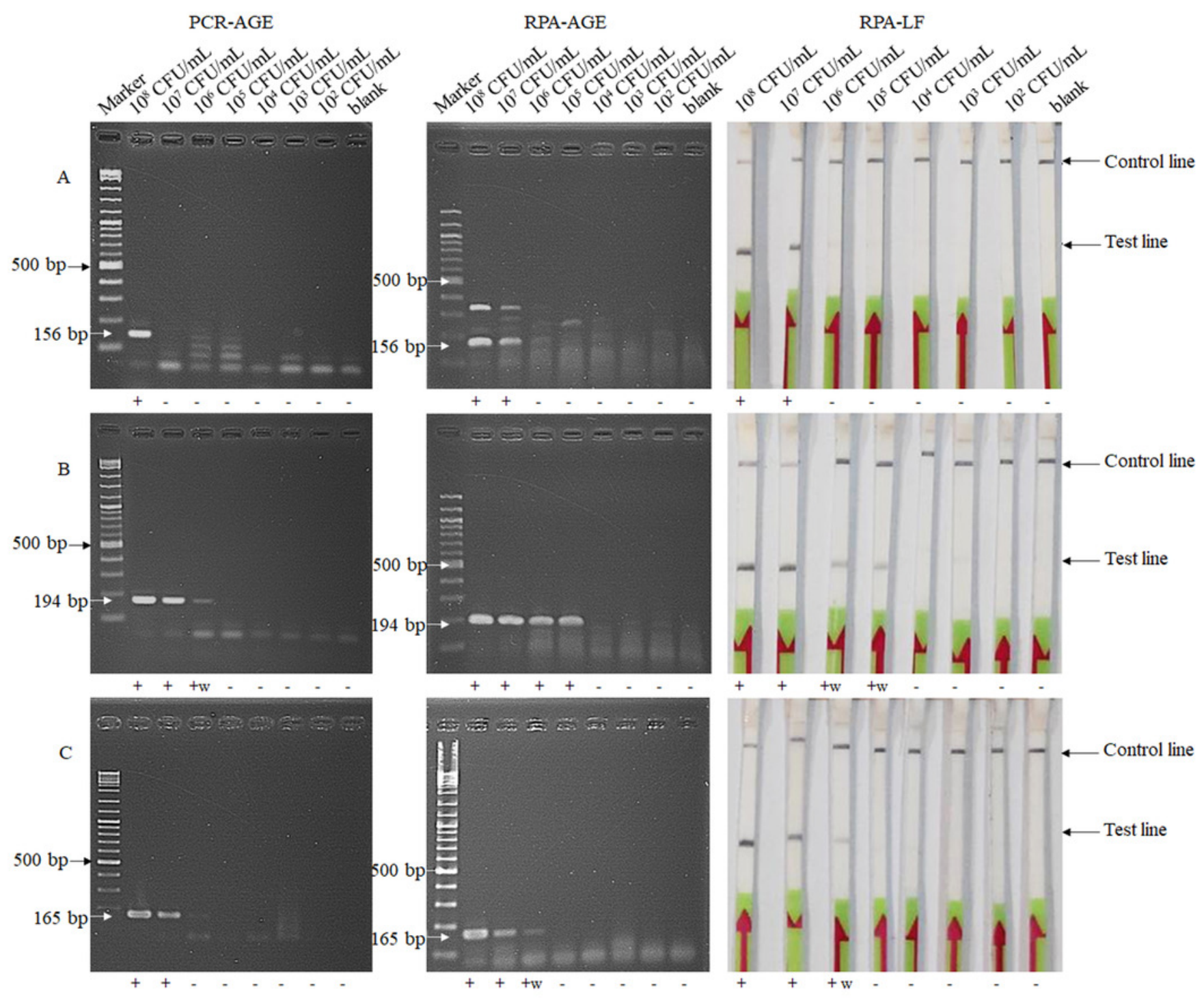

